\title{
Publisher Correction: On-chip sampling of optical fields with attosecond resolution
}

Mina R. Bionta (D), Felix Ritzkowsky (1), Marco Turchetti (D), Yujia Yang (1), Dario Cattozzo Mor (D), William P. Putnam (1), Franz X. Kärtner (D), Karl K. Berggren (i) and Phillip D. Keathley (1)

Correction to: Nature Photonics https://doi.org/10.1038/s41566-021-00792-0, published online 15 April 2021.

In the version of this Article originally published, the $x$ axis of the Fig. 4 a inset was incorrectly labelled $-10,0,1,0$; it should have read $-10,0,10$. The original and corrected figures are shown below.

Original
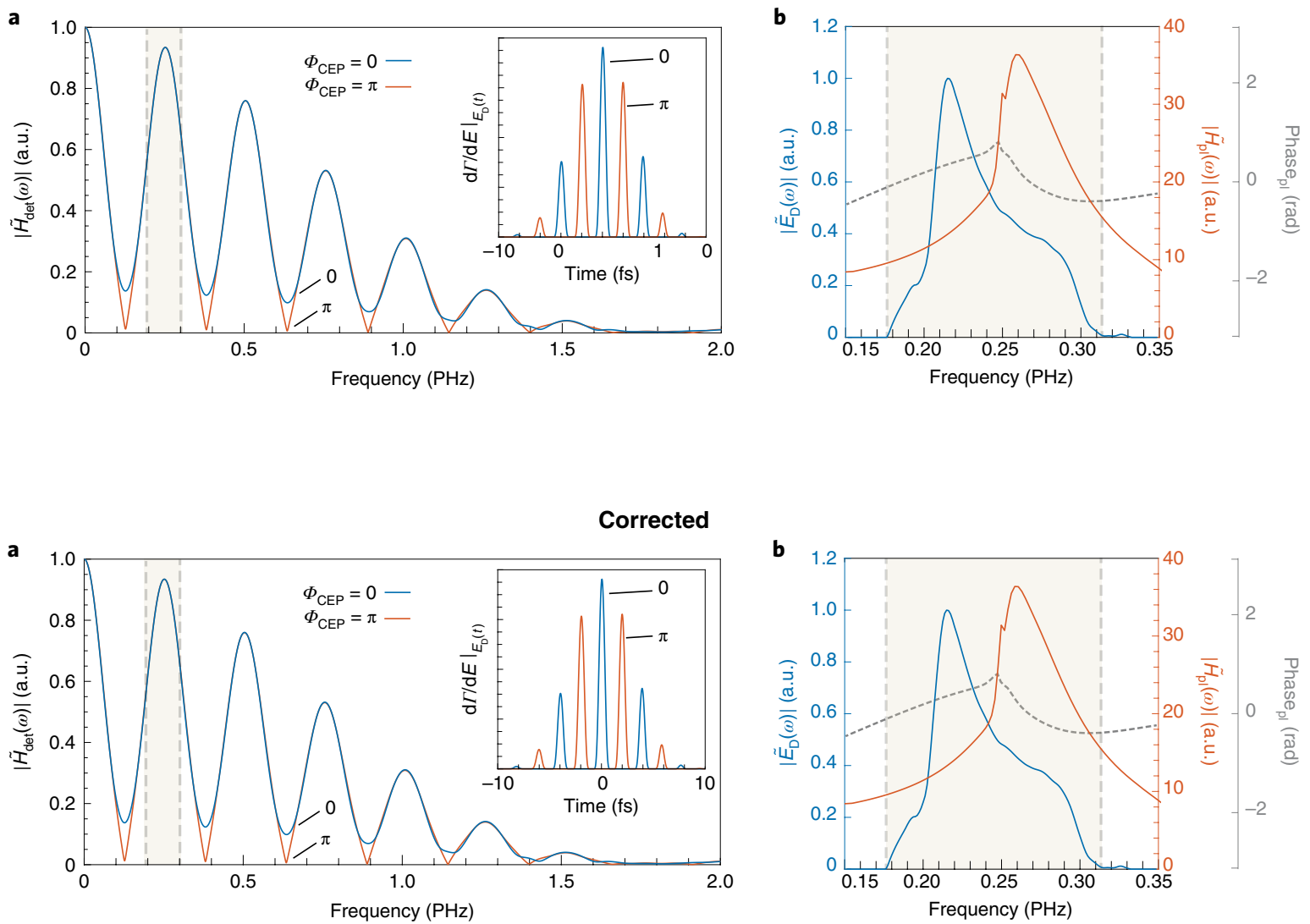

Fig. 4 | Original and corrected.

Published online: 6 May 2021

https://doi.org/10.1038/s41566-021-00821-y

๑ The Author(s), under exclusive licence to Springer Nature Limited 2021 